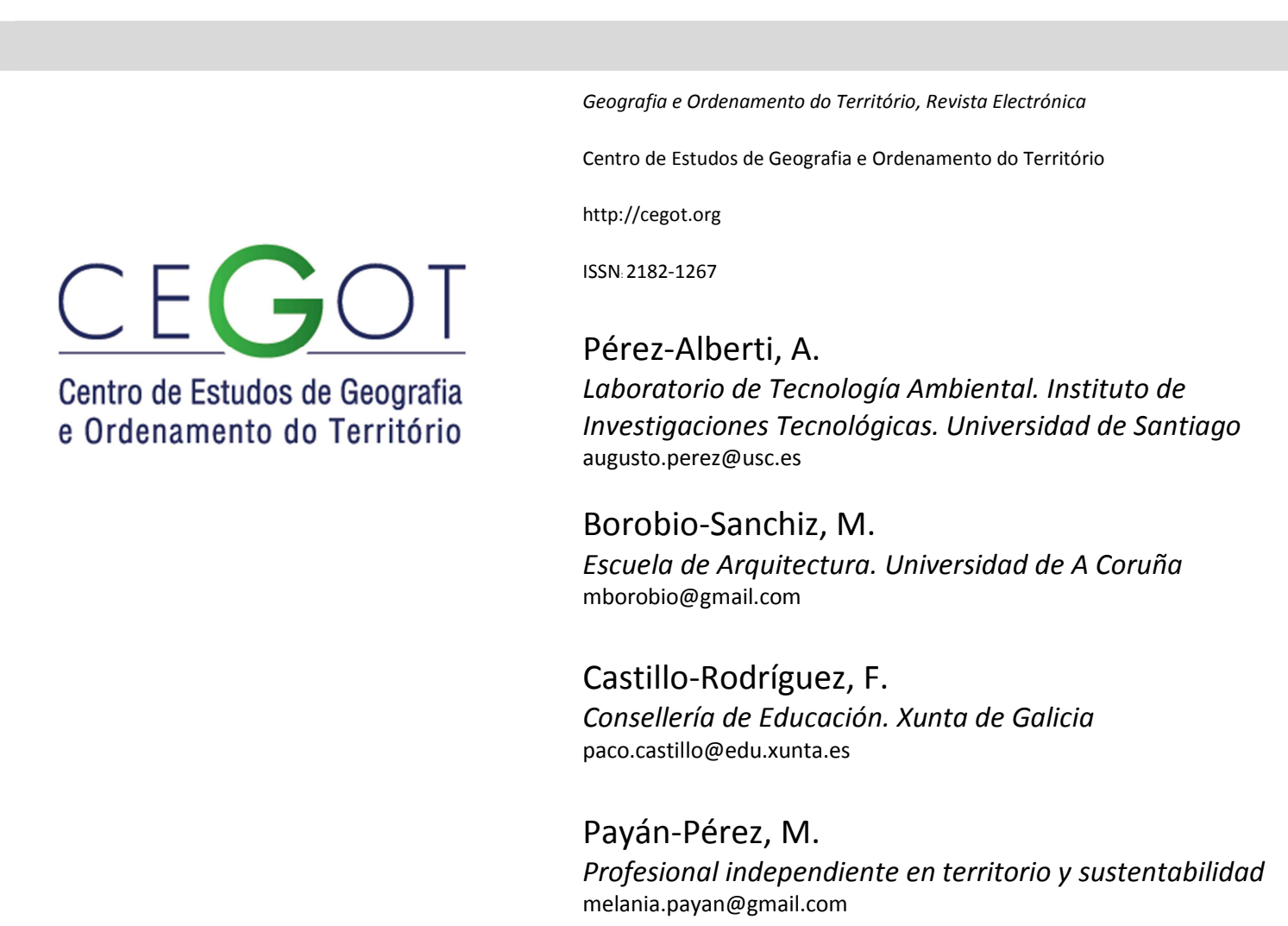

\title{
Metodología y clasificación de tipos de paisaje en Galicia
}

Referência: Pérez-Alberti, A. et. al (2014). Metodología y clasificación de tipos de paisaje en Galicia. Revista de Geografia e Ordenamento do Território (GOT), n. 6 (dezembro). Centro de Estudos de Geografia e Ordenamento do Território, p. 259-282

\section{Resumo}

Neste trabalho, apresentam-se os resultados da investigação realizada com o objetivo de caracterizar os diferentes tipos de paisagem existentes na Galiza (NW Espanha). Considerou-se a Paisagem como o resultado de um sistema dinâmico, no qual interagem elementos estruturais e texturais. Os resultados materializam-se na caracterização de seis grupos de paisagem, em função da preponderância da dinâmica natural ou antrópica e 28 tipos de paisagem sobre os quais se remete diretamente para a sua proteção, gestão e planeamento.

Palavras-chave: Galiza, Espanha, paisagem, ordenamento do território, caracterização da paisagem

\section{Resumen}

En el presente artículo se exponen los resultados de las investigaciones llevadas a cabo con el fin de caracterizar los diferentes tipos de paisaje existentes en Galicia (Noroeste de España). Se ha considerado el paisaje como resultado de un sistema dinámico en que 
interaccionan elementos estructurales y texturales. El resultado ha sido la caracterización de 6 grupos de paisaje, en función del dominio de la dinámica natural o antrópica y 28 tipos de paisaje sobre los que incidir de forma directa de cara a su protección, gestión y ordenación.

Palabras-Clave: Galicia, España, paisaje, ordenación del territorio, caracterización del paisaje.

\section{Introducción}

El estudio del paisaje viene de antiguo. No es nada reciente pese a que desde que viera la luz el Convenio Europeo del Paisaje en octubre de 2000, se han intensificado las acciones para lograr que el paisaje, la percepción visual que se tiene de todo territorio, tuviese un mayor protagonismo en la ordenación del territorio. No es fácil, sin embargo, encajar el término paisaje en una definición universal. El citado Convenio Europeo comienza su articulado expresando qué entiende por paisaje, "cualquier parte del territorio, tal y como es percibido por las poblaciones, cuyo carácter resulta de la acción de factores naturales y humanos y de sus interrelaciones".

Parece prudente sin embargo que, aceptando la definición propuesta, se potencie también su dimensión física, material y objetiva, aunque se le otorgue un papel básico a la percepción y a la memoria. Esta objetividad, imprescindible para cimentar un corpus sólido de conocimiento del paisaje, debe complementarse con los aspectos intangibles y los valores culturales que impregnan esa realidad material, vinculados a las sociedades que a lo largo del tiempo los produjeron. Parece necesario, por lo tanto, integrar todas las miradas posibles, tanto las contemporáneas como las pretéritas, de las poblaciones que viven o han vivido el paisaje objeto de análisis.

En el estudio de Ormaetchea Arenaza, O. (1997) se distinguen, por lo menos, dos grandes líneas en las investigaciones paisajísticas. Por una parte, la perceptiva, que relaciona el paisaje con una escena y, por otra, la que considera el paisaje como resultado del entramado territorial, como el fruto de la integración de factores diversos. Dentro de los estudios enmarcados en la primera línea, habría que citar los trabajos de Kates (1962), Burton \& Kates (1964), Lowental \& Prince (1972), Saarinen (1966, 1969, 1973), Gould (1967), Penning-Rowsell (1973) y, muy especialmente, Smardon, R.C. 
(1979). Una buena síntesis de los trabajos realizados se puede ver en Zube, Sell \& Taylor (1982), o en Rougerie \& Beroutchachvili, (1991). Dentro de la segunda, son pioneros los trabajos de Bertrand (1968), Bertrand \& Dollfus (1973); Tricart \& Kilian (1982) o Farina (1995).

\subsection{El paisaje como sistema}

Admitiendo que un paisaje existe en tanto que es percibido por un observador, la variedad de la percepción es siempre grande y varía de una persona a otra, por lo que es preciso apuntar que la percepción es algo dinámico dado que no todas perciben lo mismo. Por otra parte, el paisaje no sólo es percepción es mucho más; es el resultado siempre inestable de una dinámica en la que intervienen elementos bióticos, abióticos y antrópicos (Pérez Alberti, 2001). Por eso, si bien es importante lo perceptivo en la comprensión de los paisajes, parece necesario ir más allá y entrar en su dialéctica concreta fruto de gran número de elementos, factores y procesos a lo largo del tiempo. De la dominancia de unos u otros surge una u otra tipología de paisaje. Si los que dominan son elementos bióticos, por ejemplo árboles, aparece delante de los ojos del observador un paisaje bien diferente del existente si dominan los abióticos, por ejemplo, salientes rocosos. Y los paisajes son distintos si los dominantes son elementos antrópicos. Simplificando, se puede decir que en función de su grado de presencia pueden aparecer en el territorio paisajes urbanos o rurales. En los primeros los dominantes son los elementos artificiales, mientras que en los segundos se mezclan lo artificiales con lo bióticos y los abióticos.

El paisaje, pues, no conviene tampoco verlo únicamente como algo estático sino como algo dinámico, fruto de un juego dialéctico a lo largo del tiempo (Pérez Alberti, 2008). Por eso, los posibles escenarios perceptuales, no solo cambian a lo largo de los años; incluso lo hacen con el paso de las estaciones o de los días. La razón de ello, debido a causas naturales, realmente excepcionales, o antrópicas, mucho más frecuentes, motiva que en el paisaje domine la estabilidad o la inestabilidad. En el primer caso estarían aquellos que apenas cambian a lo largo de los años, como es el caso, por ejemplo, de los situados en las montañas de Galicia; en el segundo, aquellos que se transforman con 
gran rapidez, caso de los situados en muchos lugares de los entornos urbanos o agrarios de la costa o del interior gallego.

Cada paisaje, por su propia génesis, tiene una dinámica diferente. Así en Galicia existen paisajes que aparecen marcados por la evolución natural de sus elementos: bosques, aguas, o incluso los mismos campos de cultivo o los asentamientos que, en la actualidad, más que cambiar van decayendo con el paso de los años. Por el contrario aparecen otros en continua evolución, que cambian de año en año en relación a nuevas construcciones, vías de comunicación, obras públicas etc.

El paisaje pues, presenta dinámicas, tiempos y ritmos diferentes lo que hace difícil caracterizarlo y diferenciarlo. Este problema se puede afrontar por lo menos de dos formas: en relación a su dinamismo, o en función de los elementos que los componen plasmados en formas, colores, líneas o volúmenes. En el primer caso podría seguirse la metodología propuesta por Jean Tricart (1977), quien diferenciaba los paisajes entre estables, inestables e integrados; y en el segundo lugar, la de Smardon (1979), quien basaba la caracterización de los paisajes en elementos visuales como colores, texturas, líneas o volúmenes.

Parece necesario, sin embargo, combinar en cierta medida las dos visiones sin caer en el eclecticismo. Por un lado, caracterizar los paisajes teniendo presente los elementos que los construyen y cómo se manifiestan visualmente. Así, el roquedo condiciona la forma del paisaje pero también la textura, dado que no es igual un paisaje en el que dominan los granitos que aquellos en los que los elementos pétreos que lo conforman son las calizas o los esquistos, por poner un ejemplo, ni son iguales los paisajes en los que elementos dominantes son los bióticos que aquellos en los que dominan los antrópicos y, ahondando aún más, no es igual un paisaje en el que dominan los soutos de castaños o los bosques de robles, que aquellos en los que el dominante es el matorral o son las plantaciones de eucaliptos.

Y si es importante analizar el paisaje desde una óptica visual, todavía lo es más hacerlo desde su dinámica, la cual va a estar condicionada por sus propios elementos constitutivos. Estos elementos, en general, pueden ser diferenciados en estructurales y texturales, como se analizará más adelante. Entre los primeros se encuentran las rocas, el relieve, las aguas y las variables climáticas, caso de la temperatura, radiación, 
humedad, viento...; entre los segundos, las actividades antrópicas, los cultivos, las vías de comunicación, las plantaciones arbóreas, etc. Los primeros evolucionan muy lentamente, excepto cuando se producen desastres naturales, caso de grandes movimientos en masa en las laderas, inundaciones, temporales etc.; los segundos cambian con mucha más frecuencia. Por ello, los elementos estructurales, son más útiles para la delimitación de los paisajes y en especial las formas del relieve, mientras que los segundos, los texturales, facilitan su caracterización.

La línea de trabajo propuesta persigue alcanzar la comprensión de las complejas relaciones entre la estructura formal de los paisajes y todos aquellos procesos ecológicos y socioeconómicos que los construyen. Sintoniza, por tanto, con los postulados de la metodología anglosajona -Landscape Character Assessment- basada en el concepto de "carácter", entendido como "patrón diferenciable y reconocible de elementos que se presentan de forma consistente en un paisaje" -Swanwick, 2004-. Esta aproximación ecosistémica centra sus esfuerzos en desvelar la diversidad estructural del paisaje, la adaptación de la actividad humana, los equilibrios ecológicos en los paisajes de clara dominancia cultural, sin olvidar que esta mirada se completa con la lectura semiológica, es decir, los significados y representaciones sociales otorgadas a las formas del territorio.

\subsection{Escalas de análisis del paisaje}

El estudio del paisaje puede y debe enfocarse desde tres puntos de vista que se complementan entre sí: el descriptivo, el analítico y el dinámico. Éste a su vez tiene que estar asociado al evolutivo. Se trata, pues, de trabajar el paisaje como parte de un territorio que evoluciona a lo largo del tiempo. Al describir el paisaje es preciso poner el acento en los elementos que lo componen y que, consecuentemente, se interrelacionan entre sí. Al hacerlo va a aparecer sin duda la subjetividad, por lo que la descripción debe estar sustentada en el empleo de herramientas que permitan una mayor objetividad. Lo descriptivo es importante pero debe huirse de la mera enumeración, que sería, en gran medida, sinónimo de inventario, y potenciar la cuantificación y la cualificación. 
El análisis paisajístico supone relacionar los elementos presentes en cada lugar. Se trata sin duda de una tarea difícil por lo que debe ser realizada por especialistas que sean capaces de explicar los porqués, el papel de cada elemento así como de los procesos que se dan entre ellos. Esto supone combinar el trabajo de campo con el uso de herramientas que faciliten un análisis multicausal.

Conocer los cambios en los paisajes supone el estudio de las transformaciones a lo largo del tiempo. Al análisis espacial hay que unirle, pues, el temporal. Se trata de explicar cómo ha ido evolucionando un paisaje a lo largo del tiempo. Por supuesto ello va a estar condicionado por las fuentes y materiales de que se disponga pero hay que tener en cuenta que el aspecto de cualquier territorio actual es el fruto de una historia y que si el presente es el resultado del pasado, al mismo tiempo éste va condicionar el futuro.

\subsubsection{La escala temporal}

El análisis a largo plazo es preciso emplearlo si se quiere comprender la presencia y dinámica de elementos estructurales, caso del relieve o del clima, que cambian a lo largo de miles de años. Es posible hablar en este caso de tiempos largos.

El análisis a corto plazo no se puede obviar si lo que se pretende entender son las modificaciones en los elementos texturales, caso de los cultivos, las vías de comunicación, urbanizaciones, etc. En este caso se trataría de periodos de un año a un siglo.

\subsubsection{La escala espacial}

La escala de detalle, técnicamente escala grande, va a permitir entrar en el estudio pormenorizado de los elementos que configuran cada paisaje, desde la tipología de las viviendas, hasta los muros de piedra o vegetales, las formaciones arbóreas, los cultivos, las calles, los caminos, etc. Es la visión que tiene un espectador cuando amplía el zoom. Sirve para caracterizar con precisión cada paisaje y poder elaborar protocolos de actuación a nivel de lugar. 
Por contra, la escala pequeña, supone alejarnos de los lugares, abrir el objetivo visual y ver el paisaje desde lejos. Este hecho facilita la visión del mosaico que existe en cada uno de ellos. Al mismo tiempo, la visión desde la lejanía permite comprobar la relación existente entre diferentes paisajes que se encadenan en un territorio. El empleo de escalas pequeñas permite llegar a definir asociaciones tipológicas, observar, por ejemplo, el paso de un paisaje de valle a otro de ladera u otero, al tiempo que entender el papel de los escenarios, es decir, de los contextos en los que está inmerso cada paisaje. En suma, el empleo de la escala pequeña posibilita la delimitación de áreas homogéneas mientras que la escala de detalle facilita la caracterización de tipologías y, al mismo tiempo, una y otra, son básicas para llegar a elaborar una clasificación comprensible y coherente.

\subsubsection{El análisis diacrónico/sincrónico}

Por último, para llegar a la comprensión de cada paisaje es necesario llevar a cabo un análisis diacrónico y sincrónico. En el primer caso, es preciso estudiar la evolución a lo largo del tiempo. Ello va a estar muy condicionado por la existencia o no de documentación. Posiblemente esta sea más rica en los entornos urbanos que en los rurales, por lo que la existencias de imágenes aéreas históricas permitiría la creación de un momento en el tiempo a partir del que analizar un paisaje. En el caso gallego, la disponibilidad de vuelos aéreos desde el año 1956 hasta la actualidad, posibilita conocer los cambios en las coberturas y usos del suelo. Si, por otra parte, se acepta que las grandes transformaciones espaciales se han producido desde los años cincuenta del siglo pasado, será posible comprobar y analizar los impactos que éstas han tenido en el paisaje.

El análisis sincrónico permitirá, por su parte, conocer los diferentes ritmos evolutivos en áreas vecinas. Las transformaciones que sufrieron los paisajes posiblemente no sean de la misma magnitud en un lugar que los producidos en sus colindantes. Por ello, combinar sincronía y diacronía permitirá llegar a una mejor comprensión de cualquier realidad paisajística. 


\subsection{Los niveles de aproximación al paisaje.}

El primer nivel, que se puede calificar como descritivo, permite identificar los componentes o elementos que constituyen el paisaje, los cuales, pueden ser diferenciados, como ya se ha esbozado, en estructurales y texturales, en función de las características físicas de cada uno y, consecuentemente, de la escala temporal en la que evolucionen (Pérez Alberti, 2008).

- Estructurales: Aquellos que surgen de la naturaleza y evolucionan en largos períodos de tiempo, muy superiores a la historia humana a excepción de ciertos episodios que funcionan en momentos de alta intensidad y baja frecuencia, caso de la actividad volcánica o terremotos. Por ejemplo, las unidades litológicas, las formas topográficas, los suelos o las variables climáticas cambian muy lentamente.

- Texturales: Los que se derivan de la actividad de las mujeres y los hombres sobre el territorio y que cambian en períodos cortos de tiempo. Por ejemplo, una formación vegetal, un cultivo, el diseño de un asentamiento, una vía de comunicación, etc.

Y dentro de estos, se pueden clasificar como:

- Elemento caracterizador o dominante. El que se repite en los paisajes. Por ejemplo, una forma del relieve, de reestructuración de las laderas, de cultivo de entramado parcelario o una determinada tipología arquitectónica, etc.

- Elemento singular. Aquel de los anteriores que por su importancia sobresale de una manera clara en un paisaje, dándole singularidad. Por ejemplo, una cresta rocosa que sirve de escenario, piénsese en el filón de cuarzo que construye el escenario del Pico Sacro, en las cercanía de Santiago de Compostela, que aparece como telón de fondo de muchos paisajes de la comarca; un emplazamiento único (en una bocarribeira dominando un amplio valle), piénsese en la localidad orensana de Castro Caldelas cabalgando sobre los valles de la cuenca del río Sil; una reestructuración total de la topografía por medio de aterrazamientos (socalcos), caso de las Ermidas en el municipio de O Bolo, en el valle del río Bibei.

El paisaje presenta también una textura, entendiendo por tal la rugosidad o grado de la cobertura del paisaje, que surge tanto de la disposición de los diferentes elementos sobre el territorio como de sus características. Por ejemplo, en un paisaje donde domina 
el matorral el tamaño del grano es menor que allí donde existe un robledal (carballeira) $y$, por ende, los viñedos presentan una textura diferente de la de los prados y las ciudades distintas de las aldeas rurales.

En un segundo nivel de aproximación, o analítico, que se puede considerar como compositivo del paisaje, se puede apreciar que cada uno de ellos está articulado de una manera concreta. Es decir, los elementos se disponen en función de las relaciones de diferentes variables, ya sean de origen biótico, abiótico o antrópico. Las diferentes combinaciones entre elementos estructurales y texturales dan lugar a distintas composiciones escénicas de los paisajes. No se está hablando de escenarios estáticos, a modo de un teatro, sino de algo dinámico, cambiante que se modifica en función de los ritmos y tiempos vinculados a los procesos que se dan entre los distintos elementos.

La composición escénica varía de un paisaje a otro en relación a la topografía, la presencia o ausencia de agua, sea río, mar o laguna, el entramado viario, el emplazamiento de los asentamientos, el trazado de las calles, la configuración del espacio público desde la relación de las construcciones $y$, lo que no es menos importante, su ubicación respecto al horizonte. Por ello hay paisajes construidos sobre Ilanuras, que se recortan contra el cielo. Por contra, los hay que detrás de sí se levanta un fondo rocoso, una playa o una ladera cubierta de vegetación, entre otras; cuando no aparecen entre una lámina de agua, en su frente y una ladera rocosa, al fondo.

En un paisaje periurbano el grado de mezcla de elementos construidos puede ser muy variable. Puede suceder que la ciudad haya ido creciendo apoyándose en los viejos caminos, o como urbanizaciones perfectamente cuadriculadas que, a modo de parrilla, alteran la estructura del paisaje rural en el que se asientan. La gama de estructuras es, como en el caso anterior, muy variable, Por ello es preciso analizar detalladamente la composición escénica de cada paisaje para poder planificar su proceso evolutivo.

Conocidos los elementos y analizada la articulación de los paisajes y las escenas, es preciso ahondar en un tercer nivel de comprensión centrado en las dinámicas que sostienen la composición escénica del paisaje, bien a lo largo del tiempo (diacrónicas) o bien en cortos períodos (sincrónicas), con sus ciclos, ritmos, tiempos y procesos. No se debe olvidar que la dinámica es la rama de la física que describe la evolución en el tiempo de un sistema físico en relación con las causas que provocan los cambios en su 
estado. En el caso del paisaje se trata de saber cuánto y cómo evolucionó en el tiempo. Esto supone conocer tanto los diferentes elementos que entraron en juego a lo largo del tiempo y su grado de transformación.

Dicho lo anterior, la caracterización que se lleva a cabo en esta investigación comienza con el análisis conjunto de los conceptos y dimensiones de cada uno de los tres niveles de aproximación: elementos, composiciones y dinámicas. Podría parecer complejo si antes no fuesen explicados, pero una vez presentados, el análisis sistémico es precisamente el valor añadido que se aporta fruto de un estudio relacional y multidisciplinar.

\section{Metodología}

Existen trabajos en España que abordan el tema de la clasificación y caracterización del paisaje (Bolòs i Capdevila, M. (Dir.), 1992; Pérez Chacón (1995), Cancer Pomar, L. 1995; Mata Olmo, R. 2006; Mata Olmo R. et al., 2001; Mata Olmo \& Sanz Herráiz, C., 2003; Nogué, J. \& Sala, P., 2008). Sin embargo la gran fragmentación del territorio gallego y, muy especialmente, los diferentes grados de manejo, especialmente en el mundo rural (Otero Pedrayo, R., 1928; Bouhier; A. 1979) Ilevaron a los autores a diseñar una metodología que permitiese localizar, caracterizar y clasificar los paisajes de Galicia.

Para ello una primera fase de la investigación se ha basado en el análisis del terreno desde la escala pequeña, mediante un Sistema de Información Geográfica (SIG), a partir de la combinación de ortoimágenes y modelos digitales del terreno y superficies, con una resolución de hasta 1 metro píxel, de la totalidad de Galicia. Esto ha facilitado una visión cenital, que nos ha permitido comprobar las diferencias en la articulación del territorio y las relaciones entre los elementos físicos, que se pueden considerar de control, y los elementos antrópicos de caracterización.

Los primeros, caso de la topografía, controlan el manejo del suelo; los segundos, caso de los asentamientos, los cultivos, las vías de comunicación etc., son los elementos definidores o caracterizadores de los paisajes. Por ejemplo, la combinación del mapa de pendientes y la ortoimagen ha ayudado a diferenciar los distintos tipos de paisaje en relación a la topografía: laderas, oteros, fondo de valle, llanuras. Al mismo tiempo, la 
combinación de modelos del terreno, ortoimágenes y las entidades de población hizo posible identificar y tipificar los lugares analizados. En esta fase se analizaron más de 2000 lugares de Galicia.

En una segunda fase, el análisis de los asentamientos, extraídos del mapa del Sistema de Información sobre Ocupación del Suelo de España (SIOSE), permitió entender su distribución sobre el territorio, posibilitando la elaboración de mapas de densidades de entidades de población. Este hecho ayudó a entender mejor la existencia de concentración o dispersión de los núcleos de población. Por otra parte, el análisis ha permitido comprobar de forma nítida las diferencias entre la distribución y tamaño de los asentamientos existentes en las llanuras y depresiones tectónicas orensanas del sur de Galicia y aquellas que se sitúan en la Galicia central y occidental. Además, la combinación de la consideración de la litología, el modelo digital del terreno y las ortoimágenes, permitieron comprender la singularidad de ciertos paisajes como es el caso de los existentes en las vaguadas o interfluvios amplios (lombos) de la Galicia oriental lucense.

En una tercera fase, una vez hecha la tipificación paisajística con el apoyo de los análisis SIG, se llevó a cabo un laborioso trabajo de campo que ha permitido analizar con detalle tanto la presencia de los elementos físicos de control, aquellos de condicionan el uso, caso del agua, la roca, el suelo o las formaciones vegetales; como de los elementos antrópicos de caracterización, o sea los que caracterizan y singularizan los paisajes, caso de las tipologías de las viviendas rurales, muros, cierres de fincas, cultivos, las construcciones urbanas, industriales, comerciales etc.

Por último, en una fase posterior, con el objetivo de poder comparar, visibilizar y cuantificar los porcentajes de los distintos elementos existentes dentro de un sector determinado, así como las diferencias texturales de los distintos paisajes, se elaboró una malla compuesta por cuadrados de 1000 metros de lado, que buscaba abarcar dentro de cada tipo de paisaje:

a) La cantidad, diversidad y variedad de asentamientos existentes; cómo la estructura y el tamaño de cada uno de ellos incidía en la estructura del paisaje.

b) El grado de impacto de los primitivos caminos de carro y de las nuevas vías de comunicación. 
c) El uso del suelo analizando las diferencias entre las actividades agrarias, urbanas, industriales, extractivas etc., para comprobar y cuantificar cómo marcan la tipificación de los paisajes.

d) La distribución y cuantificación de la propiedad de la tierra y, consecuentemente el parcelario, dado que colabora en el diseño del mosaico paisajístico de forma especial allí donde perviven los cierres.

\section{Resultados}

El análisis de unos 2000 lugares distribuidos por todas las comarcas paisajísticas de Galicia, permitió seleccionar alrededor de 600. La presencia de unos u otros elementos y su distribución permitieron agrupar los paisajes de Galicia a TRES niveles.

a) En un primer nivel se han englobado los paisajes en GRUPOS, en función de la dinámica dominante, natural o antrópica. Así por ejemplo, en dinámica natural se han diferenciado los grupos: litopaisajes, con dominio del roquedo, caso del Monte Pindo; hidropaisajes, con dominio del agua, como la Lagoa de Doniños; biopaisajes, con dominio de la cubierta vegetal, caso de las Fragas do Eume; y en dinámica antrópica moderada, se han diferenciado los agropaisajes, en los que dominan las actividades agrarias, ganaderas o forestales, como por ejemplo los viñedos del Ribeiro; y en dinámica antrópica extrema, allí donde dominan los procesos de urbanización o industrialización, se han individualizado los paisajes urbanizados.

Además de estos dos grandes grupos dominantes se considera necesario crear el de los Paleopaisajes, en el que se integran todos aquellos cuyas dinámicas dominantes han quedado desactivadas pero aún conservan trazas características, si bien se encuentran en un proceso de abandono que, en la mayor parte de los casos en Galicia, favorece la aparición de procesos de colonización vegetal, pero que podemos considerar de dinámica mixta.

b) En un segundo nivel se clasificaron los paisajes en TIPOS en relación a la litología, la topografía y a las dinámicas de ocupación y uso: en definitva a los patrones de funcionamiento que hacen que un elemento o elementos sean dominantes, condicionando al resto. En el primer caso, el tipo de roca. En el segundo los rasgos del relieve, o sea los emplazamientos de los paisajes, marcan de forma 
nítida su configuración de manera que son visibles las formas sobre las que se desarrollan las actividades productivas, condicionando la dinámica de ocupación y al tiempo, esta modifica, en distinto grado según los lugares, la topografía, aunque sólo sea parcialmente. Así fue posible diferenciar agropaisajes sobre ladera, otero, fondo de valle etc. En los paisajes del último grupo si bien el condicionamiento del relieve es visible, el grado de ocupación del suelo enmascara la realidad topográfica. Cualquier observador puede ver que la ciudad de Ferrol se emplaza sobre una llanura costera, la de Lugo en una llanura y en el valle del Miño, A Coruña en una península o la de Vigo en un valle abierto. Sin embargo las construcciones en altura impiden ver lo que había (hay) debajo. Por ello los procesos de urbanización o industrialización llevaron a clasificar sólo en función del proceso dominante que ha construido la realidad actual del territorio.

Dicho lo anterior ha parecido más adecuado clasificar los paisajes urbanizados en los siguientes tipos: urbanos y agrourbanos, industriales, productivos intensivos, energéticos, de movilidad (puertos, aeropuertos etc.), comerciales, o de ocio y deportivos, según la función predominante en las estructuras generadas para los sistemas urbanos; y en paisajes extractivos, cuando la transformación de la topografía es total, en función de la actividad que provoca una transformación de la forma con el predominio de las actividades mineras. En un punto intermedio se sitúan los paisajes agrourbanos, en los que se mezclan los elementos residuales, derivados de la actividad agraria con los urbanos. Son especialmente visibles en los entornos de las ciudades de Galicia.

c) En un tercer nivel se pueden caracterizar los paisajes en SUBTIPOS en relación al uso concreto y a la forma de articulación del territorio: Por ejemplo: agropaisaje en ladera modificada vinícola, agropaisaje de llanura con aldea cerrada, agropaisaje de llanura con casas dispersas, etc. Nada impide crear acrónimos o generar un código para evitar nombres excesivamente largos.

Los tipos de paisaje caracterizados en Galicia se describen en la tabla 1 y se visualizan con imágenes para la mayoría de ellos en las figuras 1 y 2. 
Tabla 1: Descripción de los grupos y tipos de paisaje de Galicia

\begin{tabular}{|c|c|c|c|c|c|}
\hline GRUPO & & & TIPO & & SUBTIPO \\
\hline Dinámica & Nombre & Descripción & Nombre & Descripción & Ejemplos \\
\hline \multirow{12}{*}{$\begin{array}{l}\text { Grupos con } \\
\text { dominancia de } \\
\text { dinámica Natural } \\
\text { Paisajes en los } \\
\text { que los que } \\
\text { dominan } \\
\text { elementos y } \\
\text { procesos de } \\
\text { origen natural. }\end{array}$} & \multirow{4}{*}{ Litopaisajes } & \multirow{4}{*}{$\begin{array}{l}\text { Dominancia del roquedo. Determinante } \\
\text { la evolución geomorfológica. Aparecen, } \\
\text { bien en lugares donde la evolución del } \\
\text { relieve ha estado marcada por largos } \\
\text { procesos de alteración/erosión, bien en } \\
\text { donde se han producido procesos de } \\
\text { acumulación glaciar, fluvial eólica... } \\
\end{array}$} & Calcáreo & Modelados sobre afloramientos calizos. & \\
\hline & & & Granítico & $\begin{array}{l}\text { Modelados sobre afloramientos graníticos. La composición } \\
\text { mineralógica de la roca y su grado de fragmentación favorece } \\
\text { la existencia de paisajes singulares diferenciados. }\end{array}$ & \\
\hline & & & \multirow[b]{2}{*}{ Sedimentario } & \multirow{2}{*}{$\begin{array}{l}\text { Paisajes construidos sobre sedimentos de diferentes tipos: } \\
\text { Glaciares, fluviales, eólicos etc... }\end{array}$} & a) Morrenas \\
\hline & & & & & Dunas \\
\hline & \multirow{4}{*}{ Hidropaisajes } & \multirow{4}{*}{$\begin{array}{l}\text { Paisajes en los que domina una lámina } \\
\text { de agua fruto de una dinámica natural } \\
\text { (laguna, cascada, rápidos) o antrópica } \\
\text { (embalse). }\end{array}$} & Corriente & Corrientes de agua. & Ríos \\
\hline & & & Laminar o estancado & Masa de agua estancada. & a) Lagos \\
\hline & & & \multirow{2}{*}{ Saltos } & \multirow{2}{*}{ Rápidos de agua (cachóns) o cascadas. } & $\begin{array}{ll}\text { b) } & \text { Embalses } \\
\text { a) } & \text { Cascadas }\end{array}$ \\
\hline & & & & & b) Rápidos \\
\hline & \multirow{4}{*}{ Biopaisajes } & \multirow{4}{*}{$\begin{array}{l}\text { Paisaje en el que es dominante una o } \\
\text { varias formaciones vegetales de origen } \\
\text { natural. }\end{array}$} & \multirow{4}{*}{ Naturales } & \multirow{4}{*}{$\begin{array}{l}\text { Paisajes con dominancia de especies autóctonas en diferente } \\
\text { grao de presencia en función del manejo al que hayan estado } \\
\text { sometidas }\end{array}$} & a) Turberas \\
\hline & & & & & b) Robledales. \\
\hline & & & & & c) Devesas. \\
\hline & & & & & Encinares. \\
\hline \multirow{12}{*}{$\begin{array}{l}\text { Grupos con } \\
\text { dominancia de } \\
\text { dinámica } \\
\text { antrópica } \\
\text { Paisajes en los } \\
\text { que los que } \\
\text { dominan } \\
\text { elementos y } \\
\text { procesos de } \\
\text { origen antrópico. }\end{array}$} & \multirow{12}{*}{ Agropaisajes } & \multirow{12}{*}{$\begin{array}{l}\text { Son aquellos en los dominan las } \\
\text { actividades agrarias, ganaderas o } \\
\text { forestales. } \\
\text { Este hecho junto con la gran diversidad } \\
\text { de asentamientos (nuclear, polinuclear, } \\
\text { etc.), favorece la existencia de una } \\
\text { gran variedad de subtipos }\end{array}$} & \multirow{3}{*}{$\begin{array}{l}\text { Derivados de } \\
\text { aprovechamientos } \\
\text { forestales }\end{array}$} & \multirow{3}{*}{$\begin{array}{l}\text { Paisajes con dominio de especies arbóreas plantadas a lo } \\
\text { largo del tiempo. }\end{array}$} & a) Soutos \\
\hline & & & & & b) Pinares \\
\hline & & & & & c) Eucaliptales \\
\hline & & & \multirow{3}{*}{ Ladera retocada } & \multirow{3}{*}{$\begin{array}{l}\text { Construido sobre una ladera en la que los muros, los canales } \\
\text { de agua para el riego, las viviendas y caminos, apenas } \\
\text { retocaron el perfil topográfico }\end{array}$} & Policultivo. \\
\hline & & & & & Ganadero. \\
\hline & & & & & Vinícola \\
\hline & & & \multirow{2}{*}{ Ladera transformada } & $\begin{array}{l}\text { La ladera ha sido transformada. En general se trata de amplios } \\
\text { bancales en los que se han hecho nivelaciones del terreno } \\
\text { para lograr una mayor planitude en las parcelas. }\end{array}$ & \multirow{2}{*}{ a) Vinícola } \\
\hline & & & & $\begin{array}{l}\text { En otros lugares, especialmente en los valles fluviales del } \\
\text { Sureste de Galicia las laderas fueron totalmente transformadas } \\
\text { mediante terrazas (socalcos). }\end{array}$ & \\
\hline & & & \multirow{3}{*}{ Terraza fluvial } & \multirow{3}{*}{$\begin{array}{l}\text { Paisajes desarrollados sobre terrazas fluviales, amplios } \\
\text { escalones aplanados, antiguos niveles por los que discurría el } \\
\text { río. En otros lugares lo que domina son pequeños replanos. En } \\
\text { cualquier caso el escalonamiento al lado del río genera } \\
\text { paisajes bien diferenciados de su entorno. }\end{array}$} & Vinícola \\
\hline & & & & & b) Ganadero \\
\hline & & & & & c) Policultivo \\
\hline & & & En fondo de valle & $\begin{array}{l}\text { Se trata de paisajes construidos en fondos de valle en los que } \\
\text { la dinámica fluvial o glaciar no dio lugar a escalones. }\end{array}$ & $\begin{array}{ll}\text { a) } & \text { Policultivo } \\
\text { b) } & \text { Ganadero }\end{array}$ \\
\hline
\end{tabular}




\begin{tabular}{|c|c|c|c|c|c|}
\hline \multicolumn{3}{|l|}{ GRUPO } & \multicolumn{2}{|l|}{ TIPO } & \multirow{2}{*}{$\begin{array}{l}\text { SUBTIPO } \\
\text { Ejemplos }\end{array}$} \\
\hline Dinámica & Nombre & Descripción & Nombre & Descripción & \\
\hline & & & Interfluvio estrecho (crista) & $\begin{array}{l}\text { Paisajes construidos sobre un interfluvio estrecho con escasez } \\
\text { de terreo cultivable. Este hecho provocó la necesidad de } \\
\text { construir las viviendas en la cresta alargada y los cultivos en el } \\
\text { fondo del valle o en las laderas. }\end{array}$ & \\
\hline & & & Interfluvio ancho (lombo) & $\begin{array}{l}\text { Paisaje desarrollado sobre un amplio interfluvio aplanado, } \\
\text { existente entre dos valles por lo general encajados. A } \\
\text { diferencia del anterior, los lombos son más anchos por lo que } \\
\text { la disponibilidad de terreno para el cultivo y para emplazar el } \\
\text { asentamiento favoreció la génesis de un diseño del paisaje } \\
\text { alargado con la aldea rodeada de campos de labor mientras } \\
\text { que los prados se situaron en las laderas de enlace con el } \\
\text { fondo del valle. }\end{array}$ & a) Policultivo \\
\hline & & & Bocarribeira & $\begin{array}{l}\text { Nombre popular gallego que describe el sector del terreno que } \\
\text { se encuentra entre el valle y la planicie que lo bordea. } \\
\text { Este hecho ha favorecido la génesis de un paisaje en el que la } \\
\text { aldea se emplaza en la parte superior de la ladera } \\
\text { extendiéndose hasta el río los viñedos, mientras los cereales } \\
\text { se cultivaban en la planicie circundante. }\end{array}$ & \\
\hline & & & & $\begin{array}{l}\text { Paisajes desarrollados sobre zonas aplanadas con escasa } \\
\text { pendiente que ocupan amplios sectores de la Galicia } \\
\text { occidental y central. }\end{array}$ & a) Cerealista \\
\hline & & & Llanura & $\begin{array}{l}\text { Dentro de ellas se diferencian fosas tectónicas y superficies de } \\
\text { aplanamiento. Los contrastes topográficos, la presencia de } \\
\text { áreas con diferente pendiente y, consecuentemente, humedad, } \\
\text { suelos distintos y altitudes contrastadas desde la orilla del mar } \\
\text { hasta superar los } 1000 \mathrm{~m} \text {, ha favorecido la existencia de } \\
\text { numerosas variantes. }\end{array}$ & b) Policultivo \\
\hline & & & & & c) Ganadero \\
\hline & & & & $\begin{array}{l}\text { Se trata de zonas de contacto entre niveles aplanados a } \\
\text { diferente altitud motivados por: }\end{array}$ & a) Policultivo \\
\hline & & & Borde de llanura o fosa & $\begin{array}{l}\text { a) El paso de un sector empinado con suelos menos } \\
\text { profundos a otro de suelos más profundos y fértiles. }\end{array}$ & b) Ganadero \\
\hline & & & & $\begin{array}{l}\text { b) El paso de una zona más seca a otra de mayor } \\
\text { hidromorfía. }\end{array}$ & \\
\hline & & & Vaguadas & Amplias vaguadas, a modo de fondo de cuna, que se & a) Policultivo \\
\hline
\end{tabular}




\begin{tabular}{|c|c|c|c|c|c|}
\hline \multicolumn{3}{|l|}{ GRUPO } & \multicolumn{2}{|l|}{ TIPO } & \multirow{2}{*}{$\begin{array}{l}\text { SUBTIPO } \\
\text { Ejemplos }\end{array}$} \\
\hline Dinámica & Nombre & Descripción & Nombre & Descripción & \\
\hline & & & & $\begin{array}{l}\text { encadenan rítmicamente y se alargan, por lo general, de norte } \\
\text { a sur, bordeadas por unidades topográficas más elevadas. Se } \\
\text { trata de formas totalmente controladas por la existencia del } \\
\text { bandeado litológico existente, especialmente, en la Galicia } \\
\text { oriental. Aparecen allí donde existe una sucesión rítmica de } \\
\text { rocas con diferente resistencia a la erosión lo que motiva que } \\
\text { las más resistentes queden en resalte mientras que las de } \\
\text { menor se vayan erosionando progresivamente, y queden a } \\
\text { menor altitud apareciendo así una sucesión de crestas } \\
\text { cubiertas por vegetación y vaguadas intensamente ocupadas } \\
\text { por la población. }\end{array}$ & b) Ganadero \\
\hline & & & & $\begin{array}{l}\text { Paisajes construidos sobre una forma convexa que sobresale } \\
\text { en el territorio. Derivada de procesos de incisión fluvial. }\end{array}$ & a) Policultivo \\
\hline & & & Otero & $\begin{array}{l}\text { Los oteros marcan el diseño del paisaje cuando sobre ellos se } \\
\text { emplaza el asentamiento de la población mientras que los } \\
\text { cultivos se sitúan en las laderas de enlace con la unida inferior, } \\
\text { por lo general planicies, o sobre esta misma. }\end{array}$ & b) Vinícola \\
\hline & \multirow{7}{*}{$\begin{array}{l}\text { Paisajes } \\
\text { urbanizados }\end{array}$} & \multirow{7}{*}{$\begin{array}{l}\text { Paisajes que surgen en donde las } \\
\text { modificaciones sobre el territorio son de } \\
\text { tal magnitud que se transforman sus } \\
\text { rasgos esenciales, caso de la topografía } \\
\text { o incluso la red de drenaje y, por otra } \\
\text { parte, son mayoritarias las } \\
\text { construcciones dedicadas a vivienda, } \\
\text { comercio, industria o los equipamientos } \\
\text { y, en todo caso, necesitan del desarrollo } \\
\text { de infraestructuras e instalaciones para } \\
\text { el necesario aporte de materia y } \\
\text { energía, así como de extracción de } \\
\text { residuos, necesarios para el } \\
\text { metabolismo del sistema urbano. }\end{array}$} & Paisaje agrourbano & $\begin{array}{l}\text { Paisajes del entorno de la ciudad en el que dominan los trazos } \\
\text { urbanos aunque perviven elementos agrarios, como campos } \\
\text { de labor, casas rurales, cuando no cuadras para los animales o } \\
\text { alpendres }\end{array}$ & \\
\hline & & & Paisaje urbano & $\begin{array}{l}\text { Paisaje totalmente transformado por la ciudad. Dominio de los } \\
\text { elementos constructivos urbanos, lo que motiva la desaparición } \\
\text { de lo agrario }\end{array}$ & \\
\hline & & & $\begin{array}{l}\text { Paisaje industrial y de la } \\
\text { energía }\end{array}$ & $\begin{array}{l}\text { Paisajes en el que dominan las construcciones industriales: } \\
\text { torres, chimeneas, etc. y paisajes que han surgido en el } \\
\text { entorno de la producción y suministro de energía, como las } \\
\text { centrales térmicas, nucleares, los parques eólicos, las redes } \\
\text { hidroeléctricas etc. }\end{array}$ & \\
\hline & & & Paisaje de movilidad & $\begin{array}{l}\text { Autopistas, puertos, aeropuertos, intercambiadores... centros } \\
\text { logísticos con líneas de ferrocarril, etc. }\end{array}$ & \\
\hline & & & Paisaje comercial & Paisajes dominados por la actividad comercial y de servicios. & \\
\hline & & & Paisaje de ocio y deportivo & $\begin{array}{l}\text { Paisajes caracterizados por las actividades asociadas al ocio y } \\
\text { el deporte: campos de golf, parques acuáticos, ciudades } \\
\text { deportivas, etc. }\end{array}$ & \\
\hline & & & $\begin{array}{l}\text { Paisajes productivos } \\
\text { intensivos }\end{array}$ & $\begin{array}{l}\text { Paisajes que han surgido en los últimos decenios en relación a } \\
\text { la puesta en marcha de nuevas actividades productivas } \\
\text { intensivas primarias. Como es el caso de las grandes granjas } \\
\text { de ganado para la alimentación, grandes superficies de } \\
\text { monocultivos intensivos o bajo plásticos, las piscifactorías, } \\
\text { polígonos de bateas para el cultivo del mejillón, etc. }\end{array}$ & \\
\hline
\end{tabular}




\begin{tabular}{|l|l|l|l|l|}
\hline GRUPO & Nombre & Descripción & Nombre & Descripción \\
\hline Dinámica & & Paisaje extractivo & $\begin{array}{l}\text { Paisaje en el que las actividades extractivas motivaron la total } \\
\text { modificación del terreno apareciendo tanto grandes huecos } \\
\text { como sectores de acumulación de escombros }\end{array}$ \\
\hline $\begin{array}{l}\text { Dominancia } \\
\text { Mixta } \\
\text { Se corresponden } \\
\text { con aquellos } \\
\text { paisajes cuyos } \\
\text { procesos y } \\
\text { dinámicas } \\
\text { dominantes han } \\
\text { sido abandonados } \\
\text { o desactivados, } \\
\text { quedando huellas } \\
\text { claras y legibles } \\
\text { de dichas } \\
\text { dinámicas } \\
\text { previas. }\end{array}$ & Paleopaisajes & $\begin{array}{l}\text { El abandono favorece la colonización } \\
\text { vegetal y el renacer de las dinámicas } \\
\text { naturales }\end{array}$ & Paleopaisajes & \\
\hline
\end{tabular}



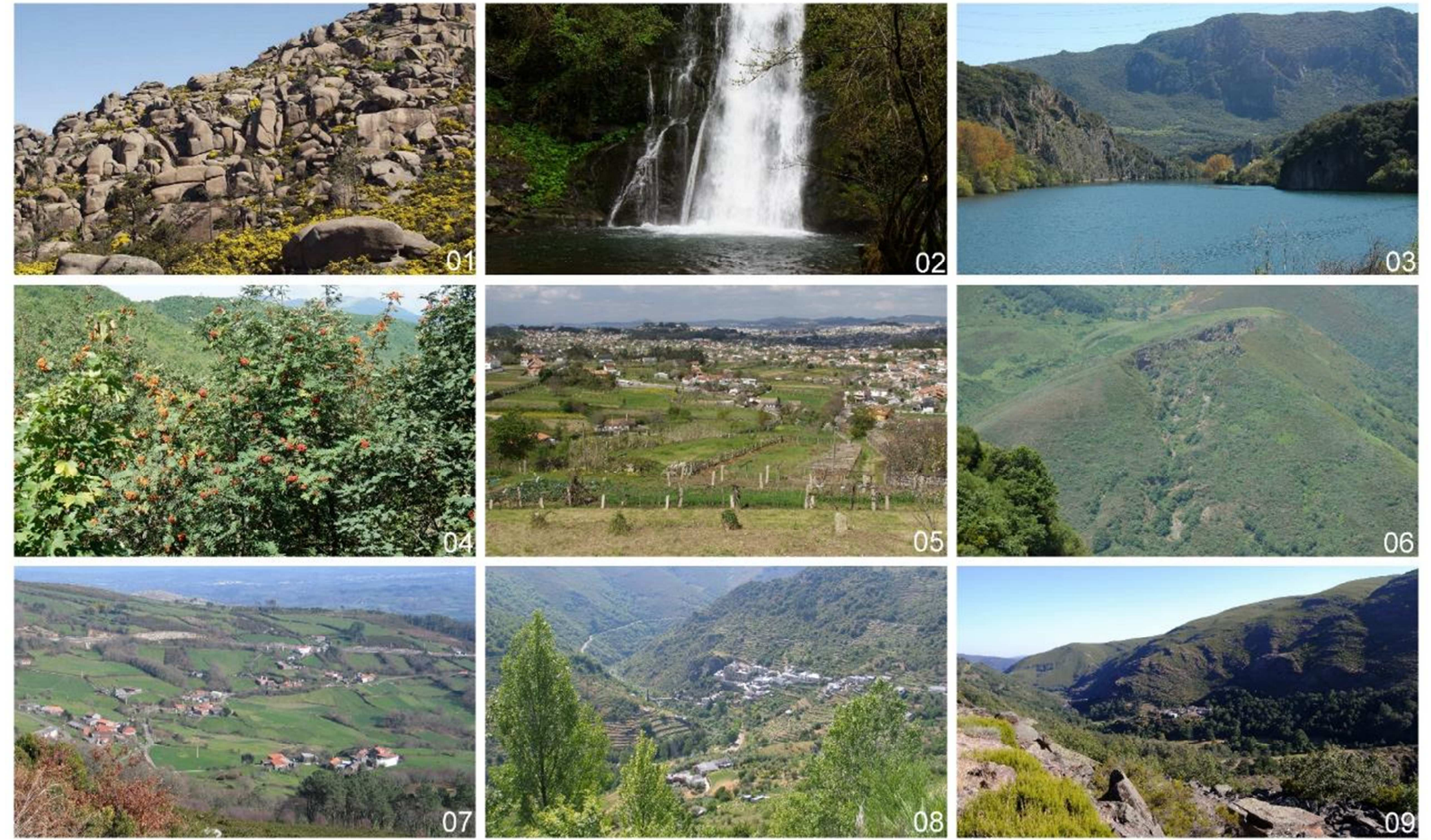

Figura 1: Composición 1 de imágenes de ejemplo de tipos de paisajes de Galicia

01: Litopaisaje granítico. Monte Pindo (A Coruña)

04: Biopaisaje natural. O Courel (Lugo)
07: Agropaisaje de ladera retocada. Lalín (Pontevedra)
02: Hidropaisaje de salto. Cascada de Vieiros (Lugo) . Paisaje urbanizado agrourbano. Vigo (Pontevedra) : Agropaisaje de ladera transformada. As Ermidas (Ourense)
03: Hidropaisaje laminar. Río Sil embalsado en Covas (Ourense)

06: Paleopaisaje extractivo. Mina da Toca (Lugo) 

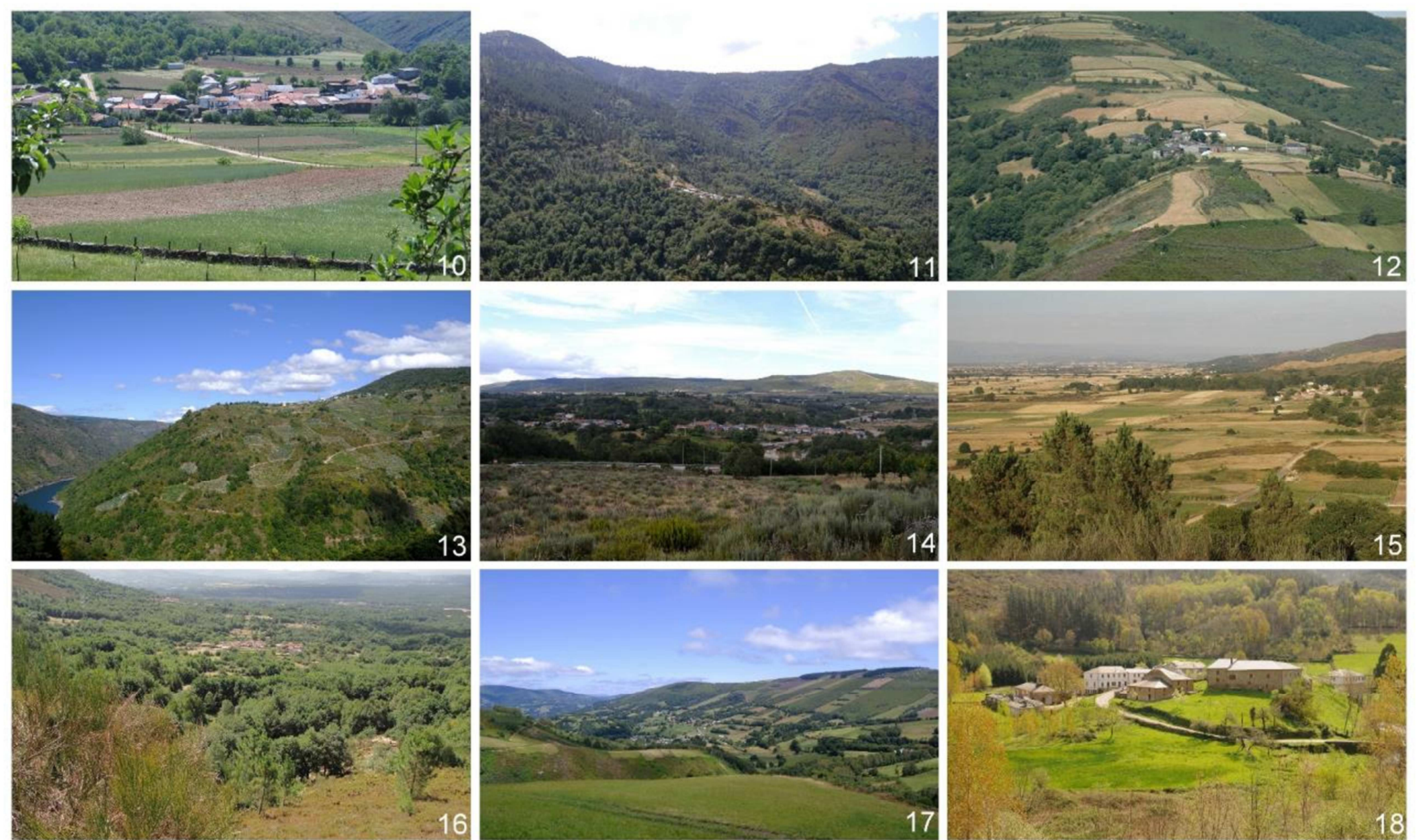

Figura 2: Composición 2 de imágenes de ejemplo de tipos de paisajes de Galicia

10: Agropaisaje en fondo de valle. Pradocabalos (Ourense) 13: Agropaisaje en bocarribeira. Cristosende (Ourense)
16: Agropaisaje en borde de fosa. Maceda (Ourense)
11: Agropaisaje de interfluvio en cresta. Castro Portela (Lugo) 14: Agropaisaje de llanura. O Pereiro (Ourense)
12: Agropaisaje de interfluvio en lombo. Ancares (Lugo) 15: Agropaisaje en borde de llanura. A Limia (Ourense) 


\section{Discusión y Conclusiones}

Tal como se decía en el apartado de metodología, existen numerosos trabajos aplicados con el objetivo de caracterizar los paisajes en diferentes comunidades autónomas de España (Catalunya, Murcia, Aragón, Andalucía...). En cada una de ellas se ha optado por una metodología, clasificación y cartografía. En cualquier caso no se llegan a definir los tipos de paisaje como se propone en el presente trabajo y se observa una relación casi directa entre los usos del suelo y los tipos de paisaje propuestos. Lo anterior, si bien permite conocer la diversidad textural de los paisajes, no desvela su funcionamiento dinámico.

La clasificación que se propone para Galicia permite no sólo conocer los rasgos texturales, y consecuentemente visuales del paisaje, sino que va más allá al presentar los tipos de dinámicas existentes (natural o antrópica), los elementos físicos (forma, pendiente, orientación, suelo, agua) y antrópicos (asentamientos, vías de comunicación, grado de urbanización) que controlaron o controlan la dinámica actual del paisaje. Este hecho permite elaborar para cada tipo de paisaje unos protocolos de actuación que favorezcan su evolución ordenada y eviten o amortigüen al máximo su degradación.

El conocer los elementos que están presentes en cada paisaje, piénsese en los materiales de construcción de las viviendas, el modo de articular los sistemas de riego o los cierres, en los agropaisajes, la gama de colores de los biopaisajes, cuando no el sistema de explotación de los extractivos, sin olvidar las relaciones entre el agro y lo urbano, puede ayudar a poner en marcha políticas de delimitación de áreas de especial interés paisajístico, entendiendo por tales aquellas porciones del territorio en las que se agrupan tipologías de paisaje semejantes o diversas en donde se conservan en buen estado los elementos que han configurado los paisajes originales. Al mismo tiempo, el conocer cuáles son los rasgos que caracterizan los diferentes paisajes puede contribuir en la necesaria puesta en marcha de la política de protección, ordenación y gestión del paisaje. Así, a través de los instrumentos de planificación de paisaje se podrían concretar estrategias de rehabilitación de lugares en los que, por las razones que fuese, se están perdiendo los rasgos que caracterizaban el paisaje original.

Dicho lo anterior parece importante reflexionar sobre si lo prioritario es tipificar y caracterizar los paisajes, como se propone en el presente trabajo, o poner el acento en la 
delimitación cartográfica de las unidades de paisaje que, a modo de inventarios, se hace en buena parte de los documentos de existentes.

Cartografiar supone representar la realidad, delimitar supone poner límites a una realidad que, en el caso del paisaje, es continua y está en continua evolución. La práctica habitual en el trazado de los límites, sean fronteras administrativas o de unidades paisajísticas, supone marcar líneas que separan realidades que son, dependiendo de la escala y enfoque de la observación, en gran medida uniformes.

Así por ejemplo, si se piensa en los agropaisajes, ¿dónde se pone el límite?: ¿en el borde de los cultivos?, ¿dónde comienza una masa de bosque o matorral?, ¿en el lugar donde se observa un cambio en la especie dominante? Sin duda la respuesta no es directa si trascendemos del mero mosaico de usos y texturas y tratamos de comprender los procesos y relaciones que configuran la escena sobre la que observamos el desarrollo de un episodio de esta obra que conforma el paisaje. Si lo que se quiere delimitar son paisajes urbanizados, ¿el límite está en los elementos construidos? En este caso, ¿dónde se pone ese borde?: ¿siguiendo la línea administrativa del parcelario?, ¿de la clasificación urbanística del suelo? o ¿allí donde la altura de los edificios es menor?

En ambos ejemplos, se puede llevar a cabo una delimitación cartográfica precisa, no hay problema técnico dado que existen herramientas que lo permiten. Sin embargo, hay que tomar una decisión y ésta ha de estar fundamentada en la finalidad última del trabajo que no es otra, que la protección, gestión y ordenación del paisaje. Finalidad que en la práctica habitual ha conducido a delimitar el territorio en "unidades de paisaje". Unidades que en unos casos han buscado dar respuesta a las necesidades de organización de la información del documento de planificación, resultando micro delimitaciones útiles para difundir y educar pero no para gestionar el día a día. En otros casos, han partido de una realidad administrativa que ha condicionado la aproximación detallada, en otros se ha limitado a la división del territorio por los bordes de cuenca fluvial o cambio brusco en la topografía. Es posible pero puede suceder, como en el caso de Galicia, que la línea se trace por un interfluvio separando tipos de paisaje que se han construido en los interfluvios o en las zonas de contacto.

Las razones expuestas, y la experiencia de los documentos de planificación elaborados en Galicia, han llevado a los autores a poner el acento en la caracterización dejando la 
delimitación para crear comarcas en las que se repiten tipos de paisajes semejantes o áreas marcadas por la topografía en las que dominan elementos estructurales similares, caso de formas del relieve, litología o clima que condicionan sin duda los tipos de paisaje.

En conclusión:

1) La diversidad de elementos físicos y antrópicos en Galicia es de gran riqueza y elevada complejidad por las mezclas y relaciones existentes entre ellos.

2) Su distinto grado de presencia y dinámica evolutiva explica la diversidad de paisajes existentes que se encuentran en distinto grado de conservación.

3) Asumir que el paisaje es un continuo cambiante obliga a considerar en un primer nivel de aproximación y observación la clasificación en GRUPOS en función de la dinámica, ya sea de dominancia natural (litopaisajes, hidropaisajes y biopaisajes), o de dominancia antrópica (agropaisajes, paisajes urbanizados).

4) Bajo esas dinámicas y en función de los procesos que en el territorio se dan, se puede observar qué elementos son los que lo caracterizan y cuáles son las funciones dominantes que cualifican ese paisaje. Es aquí donde se caracterizan 28 TIPOS, que en función de sus valores y singularidades, deberán ser receptores de las acciones directas de la gestión, protección y ordenación. Así se proponen los siguientes: calcáreo, granítico, sedimentario (litopaisajes); laminar, estancado, saltos (hidropaisajes); y naturales, derivados de explotaciones (biopaisajes); de ladera modificada, ladera transformada, terraza fluvial, en fondo de valle, interfluvio estrecho (crista), interfluvio ancho (lombo), bocarribeira, llanura, borde de llanura o fosa, vaguadas y otero (agropaisajes ); y paisaje agrourbano, paisaje urbano, paisaje industrial y de energía, paisaje de movilidad, paisaje comercial, paisaje de ocio y deporte, paisaje productivo intensivo, paisaje extractivo, así como paleopaisajes.

5) En un tercer nivel se pueden caracterizar los paisajes en SUBTIPOS en relación al uso concreto, el mosaico y a la forma de articulación del territorio, en definitiva, en relación a los aspectos texturales. 


\section{Referencias}

Bertrand, G. (1968). "Paysage et géographie physique globale. Esquisse métodologique". Revue Géographique des Pyrénnées et du Sud-Ouest, XXXIII, 3: 129-143. Toulouse.

Bertrand, G. e Dollfus, O. (1973). “Le paysage et son concept". L’Espace Géographique, 3: 161-164.

Bolòs i Capdevila, M. (dir.) (1992): Manual de Ciencia del paisaje: Teoría, métodos y aplicaciones. Masson, Barcelona.

Bouhier, A. (1979): La Galice: essai géographique s'analyse e d'interpretation d'un vieux complexe agraire, 2 vols. La Roche-sur-Yon (Vendée), s.n. (Imp. Yonnaise), 1510 páxs.

Burton, I. y Kates, R. F. (1964). The flood plained and the seashore. Geographical Review, LIV: 366-385.

Cancer Pomar, L. (1995). Ecogeografía de los paisajes del Alto Gállego. Publicaciones del Consejo de Protección de la Naturaleza de Aragón, Serie Investigación, no 1, Zaragoza, 319 pp.

Farina, A. (1995). "Introduction to Landscape Ecology as a problem solving oriented transdisci- plinary science". En EQUIP: Ponencias al II Congreso de Ciencia del Paisaje: Paisaje y Medio Ambiente. pp. 93-98. Monografies de l'EQUIP, o 6. Equip Universitari d'Investigació del Paisatge, Universitat de Barcelona.

Gómez Zotano, J. y Riesco Chueca. P. (2010): Marco conceptual y metodológico para los paisajes españoles. Aplicación a tres escalas espaciales. Consejería de Obras Públicas y Vivienda. Junta de Andalucía

Gould, P. (1967). Structuring information of spacio-temporal preferences. Journal of Regional Science, 7 (2): 259-274.

Kates, R.W. (1962). Hazard and choice perception in flood plain management. University of Chicago, Department of Geography Research Paper, N. 78.

Lowenthal, D. y Riel, M. (1972). The nature of perceived and imagined environments. Environment \& Behavior, 4: 189-207.

Mata Olmo, R. (2006). Un concepto de paisaje para la gestión sostenible del territorio, en Mata Olmo, R. y Tarroja, A. (2006). El paisaje y la gestión del territorio. Criterios paisajísticos en la ordenación del territorio y el urbanismo. Barcelona, Diputació de Barcelona-CUIMP, pp.17-40.

Mata Olmo, R.; Gómez Mendoza, R. y Fernández Muñoz, S. (2001). Paisaje, calidad de vida y territorio. Análisis Local, no 37, pp. 27-40.

Mata Olmo, R. y Sanz Herráiz, C. (dirs.) (2003). Atlas de los paisajes de España. Madrid, Ministerio de Medio Ambiente, 788 págs.

Nogué, J, y Sala, P. (2008): El paisaje en la ordenación del territorio. Los catálogos del paisaje de Cataluña. Cuadernos Geográficos, 43-2, 69-98

Ormaetxea, O. (1997): Concepto y métodos en paisaje. Una propuesta docente. Lurralde, 20, 333-544.

Otero Pedrayo, Ramón (1928): Paisajes y problemas geográficos de Galicia, Compañía Ibero-Americana de Publicaciones, Madrid.

Pérez-Chacón Espino, E., 1995. Ciencia del Paisaje y Planes de Ordenación Territorial. In II Congreso de Ciencia del Paisaje "Paisaje y Medio Ambiente" : 12, 13 y 14 de septiembre de 1994. Barcelona, p. 27.

Pérez Alberti, A. (2001): A paisaxe como sistema: o exemplo de Galicia.In Perez Alberti, A. (Ed.): O feito diferencial galego. As paisaxes de Galicia. Museo do Pobo Galego. Santiago de Compostela. pp. 57-106.

Pérez Alberti, A. (2001): La ingenieria y la geodinámica del paisaje. Revista Obras Públicas, Ingenieria y Territorio no 54, pp. 62-71.

Pérez Alberti, A. (2008): As Paisaxes de Galicia. En Reza, X.B y Cortina, A. Protección. Xestión e Ordenación da Paisaxe en Galicia. Xunta de Galicia, Santiago de Compostela. pp. 117-130.

Penning-Rowsell, E.C. (1973). Alternative approaches to landscape appraisal and evaluation. Middlesex Polytechnic Plann. Res. Group, Middlesex, Rep., 11. 
Pitt, D.G. y Zube, E.H. (1979). The Q-Sort method:Use in Landscape Assesment Research and Landscape Planning. Pp. 227-234. Proc. Nat. Conf. Applied techniques for analysis and management of visual resource. Nevada. USA. USDA.

Rougerie, G.y Beroutchachvili, N. (1991). Géosystèmes et paysages. Bilan et méthodes. Armand Colin, Paris, 302 pp.

Saarinen, T. F. (1969). Perception of the Environment. Whasington, Association of American Geographers, Commission on College Geography, Resource Paper, 5.

Saarinen, T.F. y COOKE, R.V. (1971). Public perception of environmental quality in Tucson, Arizona. Journal of the Arizona Academy of Science, 6: 260-274.

Smardon, R.C. (1979). Prototype Visual Impact Assesment Manual. University of Nwe York.

Swanwick, C., 2004. The assessment of countryside and landscape character in England: an overview. In: Bishop, K. and Phillips, A. eds. Countryside planning: new approaches to management and conservation. Earthscan, London, 109-124.

Tricart, J. y Kilian, J. (1982). La Ecogeografía y la ordenación del medio natural. Anagrama, Barcelona, 288 pp.

Zube, E., Sell, J. y Taylor, J. (1982). Lanscape perception: Research, application and the- ory. Lanscape Planning, 9, 1-33. 